\title{
Theoretical investigation of carbon defects and diffusion in $\alpha$-quartz
}

\author{
Christof Köhler, ${ }^{1,4}$ Zoltán Hajnal, ${ }^{1,2}$ Péter Deák, ${ }^{3}$ Thomas Frauenheim, ${ }^{1}$ and Sándor Suhai ${ }^{4}$ \\ ${ }^{1}$ Theoretische Physik, FB6, Universität-GH Paderborn, Warburger Str. 100, D-33095 Paderborn, Germany \\ ${ }^{2}$ Research Institute for Technical Physics and Materials Science, P.O.B. 49, H-1525 Budapest, Hungary \\ ${ }^{3}$ Department of Atomic Physics, Budapest Univeristy of Technology and Economics, Budafoki út 8, H-1111 Budapest, Hungary \\ ${ }^{4}$ German Cancer Research Center, Department of Molecular Biophysics, Im Neuenheimer Feld 230, D-69120 Heidelberg, Germany
}

(Received 11 April 2001; published 8 August 2001)

\begin{abstract}
The geometries, formation energies, and diffusion barriers of carbon point defects in silica ( $\alpha$-quartz) have been calculated using a charge-self-consistent density-functional based nonorthogonal tight-binding method. It is found that bonded interstitial carbon configurations have significantly lower formation energies (on the order of $5 \mathrm{eV}$ ) than substitutionals. The activation energy of atomic $\mathrm{C}$ diffusion via trapping and detrapping in interstitial positions is about $2.7 \mathrm{eV}$. Extraction of a $\mathrm{CO}$ molecule requires an activation energy $<3.1 \mathrm{eV}$ but the $\mathrm{CO}$ molecule can diffuse with an activation energy $<0.4 \mathrm{eV}$. Retrapping in oxygen vacancies is hindered-unlike for $\mathrm{O}_{2}$ - by a barrier of about $2 \mathrm{eV}$.
\end{abstract}

DOI: $10.1103 /$ PhysRevB.64.085333

PACS number(s): 66.30.Jt, 73.20.-r, 81.65.Mq

\section{INTRODUCTION}

Defects in $\mathrm{SiO}_{2}$ have received much attention over the last decades because of the outstanding importance of this material as an insulating layer in microelectronic devices. Research has been focused mainly on the properties of the native defects as well as of the dopants used in Si device technology. Comparatively little is known, however, about other impurities, e.g. carbon, in $\mathrm{SiO}_{2}$.

With the advent of SiC-based devices, for which $\mathrm{SiO}_{2}$ is also the native oxide, the behavior of carbon inside $\mathrm{SiO}_{2}$ became a major issue. $\mathrm{SiC} / \mathrm{SiO}_{2}$ interface-state concentrations are orders of magnitude above those of $\mathrm{Si} / \mathrm{SiO}_{2},{ }^{1}$ and carrier traps inside the oxide layer ${ }^{1}$ generally degrade device performance. Furthermore, there are signs of interface features unknown for $\mathrm{Si}$, related to incomplete removal of carbon. Spectroscopic studies ${ }^{1}$ suggest the presence of $\mathrm{C}$ nanoclusters at the $\mathrm{SiC} / \mathrm{SiO}_{2}$ interface, giving rise to defect states resembling defects in amorphous hydrogenated carbon, $a-\mathrm{C}: \mathrm{H}$. In recent experiments ${ }^{2}$ it has been shown that excess oxygen is needed to extract carbon atoms of such layers, and the resulting $\mathrm{C}-\mathrm{O}$ species diffuses fast in high-quality $\mathrm{SiO}_{2}$.

There are also experimental indications ${ }^{3}$ that during oxidation of $\mathrm{SiC}$ the outdiffusion of carbonaceous species is a fast process. The oxidation rate has been thought to be limited by the indiffusion of oxygen. ${ }^{3}$ Experimental estimates for the activation energy of oxygen diffusion in vitreous silica range from $4.7 \mathrm{eV}$ (Ref. 4) for an atomic lattice diffusion mechanism to $1.17 \mathrm{eV}$ (Ref. 5) for the molecular diffusion. Theoretical works in ideal crystalline $\mathrm{SiO}_{2}$ lead to lower barrier heights than observed in experiment due to the lack of the traps represented by the Si dangling bonds of real vitreous silica. Hamann ${ }^{6}$ calculated the diffusion barrier for a particular $\mathrm{SiO}_{2}$ lattice defect involving interstitial atomic oxygen, the peroxyl defect, to be $1.3 \mathrm{eV}$, whereas Chelikowsky et al. ${ }^{7}$ just recently proposed a saddle point for molecular oxygen diffusion with a barrier height of $0.7 \mathrm{eV}$. Since the strength of a single $\mathrm{Si}-\mathrm{O}$ bond is about $4.7 \mathrm{eV}$, the experimentally observed barrier for atomic $\mathrm{O}$ diffusion is probably related to dangling bond traps. Apart from that both experiment and theory predict a relatively fast $\mathrm{O}$ diffusion in high-quality $\mathrm{SiO}_{2}$. Therefore, the formation of the fast diffusing carbonaceous species from bonded carbon atoms has to be discussed as the crucial step in hindering the oxidation via slower, eventually incomplete, removal of carbon.

There are additional experiments which indicate that carbon nanoclusters may also form inside a $\mathrm{SiO}_{2}$ layer. The use of organosilanes (TEOS) in Si device technology causes the formation of a carbon-rich phase in $\mathrm{SiO}_{2} .{ }^{8}$ The fast diffusion of carbonaceous species is confirmed in this experiment, too. ${ }^{8}$ Infrared (IR) spectra obtained from a similar experiment ${ }^{9}$ show the presence of $\mathrm{C}=\mathrm{O}$ double bonds in the $\mathrm{SiO}_{2}$ layer. The IR peak intensity of this defect gradually increases with decreasing quality of the $\mathrm{SiO}_{2}$ layer. That also points to the trapping of $\mathrm{C}$ in an imperfect $\mathrm{SiO}_{2}$ network. No carbon aggregation in the oxide was found in Ref. 2 where the $\mathrm{SiO}_{2}$ layer had a very low dangling bond density to begin with.

While diffusion of oxygen in $\mathrm{SiO}_{2}$ itself has been thoroughly examined experimentally $y^{5,4,10}$ as well as theoretically, ${ }^{6,7,11,12}$ we are not aware of such detailed experimental or theoretical studies on the diffusion of carbon in $\mathrm{SiO}_{2}$. In this work therefore we focus on the basic carbonrelated defects and their diffusion mechanisms in $\mathrm{SiO}_{2}$. We first explore possible defect configurations of atomic carbon in an otherwise perfect $\mathrm{SiO}_{2}$ lattice and then calculate barriers for diffusion paths, which may lead to removal of the carbon impurity from the lattice.

\section{COMPUTATIONAL APPROACH}

For the atomistic simulation of carbon defects in $\mathrm{SiO}_{2}$ we used the self-consistent-charge density-functional-based tight-binding (SCC-DFTB) method. ${ }^{13,14}$ The predecessor ${ }^{15}$ of the SCC-DFTB approach has already been successfully applied to $\mathrm{SiO}_{2}$ systems. ${ }^{16}$ For the calculations presented herein we have constructed new basis sets for the calculation of the TB matrix elements and the repulsive pair potential. These have also been tested and provide reasonable results for de- 
TABLE I. Total energies of molecules and solids used in the calculation of defect formation energies.

$\begin{array}{lr}\mathrm{C} \text { atom in graphite } & -47.21 \mathrm{eV} \\ \mathrm{Si} \text { atom in Si bulk } & -35.29 \mathrm{eV} \\ \mathrm{O}_{2} \text { molecule } & -178.14 \mathrm{eV} \\ \mathrm{CO} \text { molecule } & -137.58 \mathrm{eV} \\ \mathrm{CO}_{2} \text { molecule } & -229.12 \mathrm{eV}\end{array}$

fects in $\mathrm{SiC}$ (Refs. 17 and 18) and for oxygen on $\mathrm{SiC}$ surfaces. ${ }^{19}$

We use crystalline $\alpha$-quartz $\left(\mathrm{SiO}_{2}\right)$ as a model substance because its topology and short-range order $^{20}$ are similar to amorphous $\mathrm{SiO}_{2}$. The optimized geometry (experimental values $^{21}$ in parentheses) of the hexagonal unit cell is $a$ $=2.49 \AA(2.46 \AA)$ and $c=5.43 \AA(5.41 \AA)$ with a Si-O bond length of $1.62 \AA(1.60 \AA)$ and a SiOSi-angle of $143.5^{\circ}\left(144.6^{\circ}\right)$. For calculating the formation energy of defects, supercells with 243 atoms were used. This size was sufficient to guarantee convergence of the formation energies with respect to variations of the number of atoms and the cell volume; the change in formation energy induced by increasing the number of atoms from 162 to 243 is less than 0.02 eV. Smaller supercells with 108 and 162 atoms were then used for the calculation of diffusion barriers to economize on computer time. The $\Gamma$-point approximation for the electronic band structure energy was found to be sufficiently accurate for all sizes. The gap size in our calculations is $9.6 \mathrm{eV}$ which is in reasonable agreement with the reported experimental value of $8.9 \mathrm{eV},{ }^{22}$ while $a b$ initio data for the band gap are about $5.59 \mathrm{eV}$ (Refs. 23-25) in recent works. Although out method is DFT based, the tight-binding formalism may compensate the well-known underestimation of semiconductor band gaps by DFT. We note, however, that this is not a systematic correction and do not generally claim good predictions of the band gap.

Formation energies were calculated with respect to the ideal $\mathrm{SiO}_{2}$ crystal, graphitic carbon, molecular oxygen, and crystalline silicon:

$$
\begin{aligned}
E_{\text {formation }}= & E_{\mathrm{SiO}_{2} \text { crystal }}^{\text {with defect }}-E_{\mathrm{SiO}_{2} \text { crystal }}^{\text {ideal }}-E_{\text {carbon atom }} \\
& +E_{\text {oxygen atom }}^{\text {oxygen molecule }}+E_{\text {silicon atom }}^{\text {silicon crystal }} .
\end{aligned}
$$

The last two terms are only added if the concentration of the two species, silicon and oxygen, changes in the supercell containing the defect with respect to the ideal $\mathrm{SiO}_{2}$ stoichiometry, i.e., for substitutional defects. The energy of the carbon atom is either the energy of one atom in graphite or the

TABLE II. Formation energies of some oxygen lattice point defects in $\mathrm{SiO}_{2}$.

\begin{tabular}{lcc}
\hline \hline & SCC-DFTB & Pacchioni and Ieranò $^{\mathrm{a}}$ \\
\hline Peroxyl defect & $1.2 \mathrm{eV}$ & $1.7 \mathrm{eV}$ \\
Oxygen vacancy & $6.1 \mathrm{eV}$ & $6.1 \mathrm{eV}$ \\
Frenkel defect & $7.0 \mathrm{eV}$ & $7.6 \mathrm{eV}$ \\
\hline
\end{tabular}

a References 28 and 30.

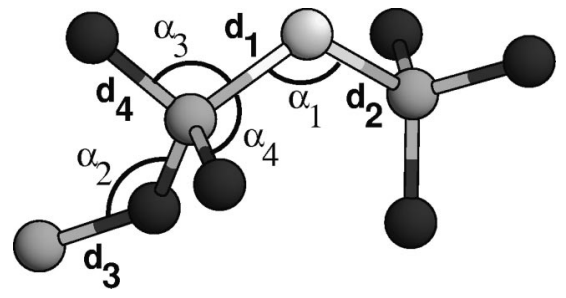

FIG. 1. Carbon on oxygen site, $\mathrm{C}_{O}$. Only the vicinity of the defect is shown. Oxygen, dark; silicon, light; carbon, white. $d_{1}$ $=1.86 \AA, d_{2}=1.86 \AA, d_{3}=1.63 \AA, d_{4}=1.63 \AA, \alpha_{1}=117^{\circ}$, $\alpha_{2}=137^{\circ}, \alpha_{3}=103^{\circ}, \alpha_{4}=109^{\circ}$.

energy in a $\mathrm{CO}$ or $\mathrm{CO}_{2}$ molecule obtained by subtracting the appropriate $\mathrm{O}_{2}$ total energy from the energy of the carbonaceous species. All defect formation energies rise by $3.77 \mathrm{eV}$ if the energy of the carbon atom in $\mathrm{CO}_{2}$ is used instead of the energy in graphite. The total energies of the molecules and the atoms in the elemental solids used in this calculation are summarized in Table I.

To find the saddle point configurations the algorithm of Kaukonen et al. ${ }^{26}$ which is based on a reaction coordinate approach, and the ART algorithm of Barkema and Mousseau ${ }^{27}$ were used.

To validate our investigations we have calculated formation energies for some oxygen lattice defects in $\mathrm{SiO}_{2}$ previously studied by Pacchioni and Ieranò. ${ }^{28}$ The results are summarized in Table II. Pacchioni and Ierano ${ }^{28}$ carried out Hartree-Fock calculations with second-order Møller-Plesset pertubation for a correlation correction on small clusters involving hydrogen atoms with fixed positions to saturate dangling bonds. Despite the very different methods and system sizes the results are in reasonable agreement. The lower formation energies in the 243-atom DFTB supercell calculation are mainly due to the higher relaxational freedom.

The diffusion of oxygen in $\alpha$-quartz through neighboring peroxyl configurations has been calculated by Hamann ${ }^{6}$ using a small 27-atom supercell (with three inequivalent $\vec{k}$ points) in a first-principles DFT generalized gradient approximation (GGA) calculation. The formation energies (with respect to the $\mathrm{O}_{2}$ molecule ${ }^{30}$ ) of the peroxyl defect and of the saddle point configuration along the diffusion path

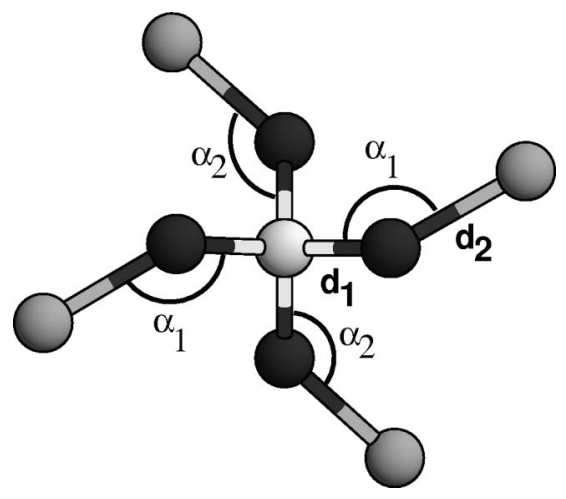

FIG. 2. Carbon on silicon site, $\mathrm{C}_{\mathrm{Si}}$. Only the vicinity of the defect is shown. Oxygen, dark; silicon, light; carbon, white. $d_{1}$ $=1.42 \AA, d_{2}=1.65 \AA, \alpha_{1}=132^{\circ}, \alpha_{2}=137^{\circ}$. 
TABLE III. Formation energies of carbon defects in $\mathrm{SiO}_{2}$ with respect to $\mathrm{O}_{2}$, graphite, and silicon bulk.

\begin{tabular}{lc}
\hline \hline $\mathrm{C}_{\mathrm{O}}$ & $10.0 \mathrm{eV}$ \\
$\mathrm{C}_{\mathrm{Si}}$ & $11.9 \mathrm{eV}$ \\
$\mathrm{CO}_{\mathrm{O}}$ & $5.6 \mathrm{eV}$ \\
Carboxyl & $4.8 \mathrm{eV}$ \\
$\mathrm{C}_{i}$ & $7.7 \mathrm{eV}$ \\
$\mathrm{CO}_{i}+\mathrm{V}_{\mathrm{O}}$ & $5.9 \mathrm{eV}$ \\
\hline \hline
\end{tabular}

were found to be $1.6 \mathrm{eV}$ and $2.9 \mathrm{eV}$, respectively (cf. Table II). Using the same supercell and a $2 \times 2 \times 3$ MP (Ref. 29) set of $\mathbf{k}$ vectors in a SCC-DFTB calculation, we obtain 1.4 $\mathrm{eV}$ and $3.2 \mathrm{eV}$, respectively. The difference in the energy of the saddle point configuration is typical between the two methods. The 162-atom unit cell ( $\mathrm{k}=0$ approximation) gave $1.2 \mathrm{eV}$ and $3.0 \mathrm{eV}$, respectively. The bond lengths of the saddle point configuration here are still within $3 \%$ of the values given by Hamann.

\section{GEOMETRIES AND FORMATION ENERGIES OF CARBON DEFECTS}

Amid the various possible carbon defects we first considered the two substitutionals, carbon on an oxygen site, $\mathrm{C}_{\mathrm{O}}$, and on a silicon site, $\mathrm{C}_{\mathrm{Si}}$. The geometries of the energetically minimized structures are shown in Figs. 1 and 2, respectively. While the $\mathrm{C}$-Si bond lengths for $\mathrm{C}_{\mathrm{O}}, 1.86 \AA$, are in the range known from $\mathrm{SiC}(1.89 \AA$ in $4 \mathrm{H}-\mathrm{SiC})$ in the case of $\mathrm{C}_{\mathrm{Si}}$ full relaxation to the usual $\mathrm{C}-\mathrm{O}$ bond lengths which could be expected for a single bond is prevented by the surrounding lattice, resulting in a bond with a $\mathrm{C}-\mathrm{O}$ distance of $1.42 \AA$. The formation energies of these two defects are the highest of all studied defects (see Table III), making them unlikely to occur in experimentally detectable concentrations in $\mathrm{SiO}_{2}$.

The other defects involve an interstitial carbon atom in an otherwise stoichiometric $\mathrm{SiO}_{2}$ lattice. The geometry of the unbonded interstitial carbon atom, $\mathrm{C}_{i}$, is shown in Fig. 3. The distance to the nearest-neighbor oxygen atom is $1.83 \AA$; the distance to the nearest-neighbor silicon atom is $2.42 \AA$.

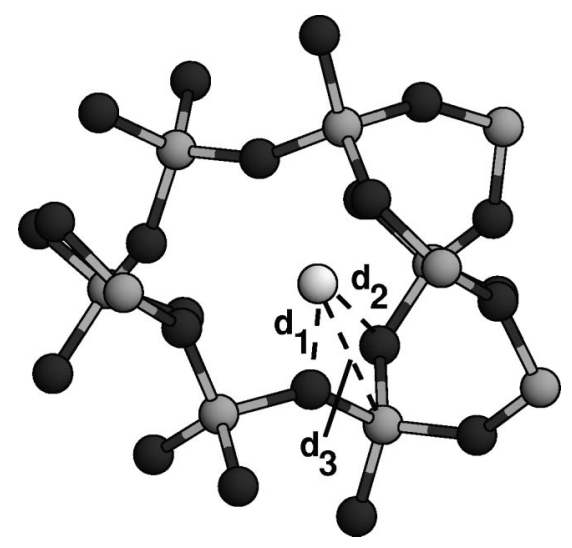

FIG. 3. Interstitial carbon atom, $\mathrm{C}_{i}$. Only the vicinity of the defect is shown. Oxygen, dark; silicon, light; carbon, white. $d_{1}$ $=1.83 \AA, d_{2}=1.95 \AA, d_{3}=2.42 \AA$.

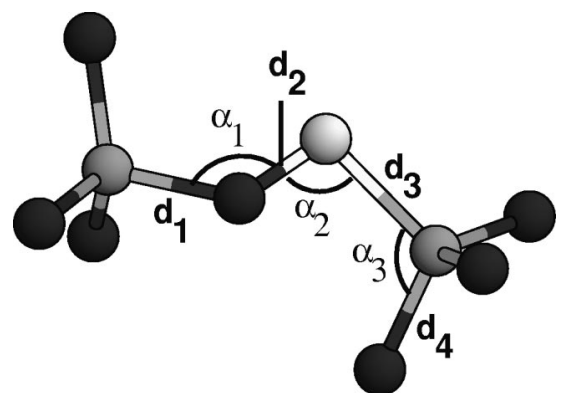

FIG. 4. Carbon and oxygen on oxygen site, $\mathrm{CO}_{\mathrm{O}}$. Only the vicinity of the defect is shown. Oxygen, dark; silicon, light; carbon white. $d_{1}=1.67 \AA, d_{2}=1.30 \AA, d_{3}=1.89 \AA, d_{4}=1.64 \AA, \alpha_{1}$ $=128^{\circ}, \alpha_{2}=125^{\circ}, \alpha_{3}=110^{\circ}$.

The formation energy of $7.7 \mathrm{eV}$ is the highest of the interstitial carbon defects.

The chemically bonded form of the carbon interstitial has two metastable configurations. The first configuration (split interstitial), denoted $\mathrm{CO}_{\mathrm{O}}$ (see Fig. 4), is similar in geometry to the peroxyl defect. The carbon and the oxygen atoms share a regular oxygen lattice site. The $\mathrm{C}-\mathrm{O}$ bond length of $1.30 \AA$ compared to $1.17 \AA$ in the $\mathrm{CO}_{2}$ molecule indicates a single bond; the $\mathrm{Si}-\mathrm{O}(1.64 \AA)$ and $\mathrm{Si}-\mathrm{C}(1.89 \AA)$ bond lengths are in the range known from $\mathrm{SiO}_{2}(1.62 \AA)$ and $\mathrm{SiC}$, respectively. The other configuration is the carboxyl defect, as depicted in Fig. 5. Here the carbon atom is on the oxygen site, bonded to the two silicon neighbors, while the oxygen atom is bonded to the carbon atom. The $\mathrm{C}-\mathrm{O}$ bond length of $1.23 \AA$, compared to $1.17 \AA$ in $\mathrm{CO}_{2}$, indicates a double bond whereas the $\mathrm{Si}-\mathrm{C}-\mathrm{Si}$ angle of $130^{\circ}$ is typical for close to $s p^{2}$-like hybridization of the carbon atom. This configuration could be the initial configuration for the removal of carbon if atomic oxygen attacks a $\mathrm{Si}-\mathrm{C}-\mathrm{Si}$ bond at the $\mathrm{SiC} / \mathrm{SiO}_{2}$ interface, provided oxygen is available, e.g., from atomic diffusion which involves the peroxyl defect.

The carboxyl and the $\mathrm{CO}_{\mathrm{O}}$ defects, shown in Figs. 5 and 4, have the lowest formation energies, $4.8 \mathrm{eV}$ and $5.6 \mathrm{eV}$, respectively (Table III). Especially in the carboxyl configuration the coordination and the chemical bonding of the atoms are ideal. Experimentally detectable concentrations of these defects could be present in $\mathrm{SiO}_{2}$ layers, especially at the $\mathrm{SiC} / \mathrm{SiO}_{2}$ interface.

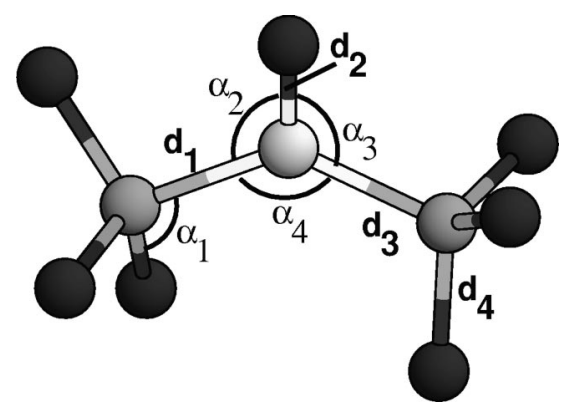

FIG. 5. Carboxyl defect. Only the vicinity of the defect is shown. Oxygen, dark; silicon, light; carbon, white. $d_{1}=1.87 \AA$, $d_{2}=1.23 \AA, d_{3}=1.88 \AA, d_{4}=1.62 \AA, \alpha_{1}=110^{\circ}, \alpha_{2}=114^{\circ}$, $\alpha_{3}=115^{\circ}, \alpha_{4}=130^{\circ}$. 


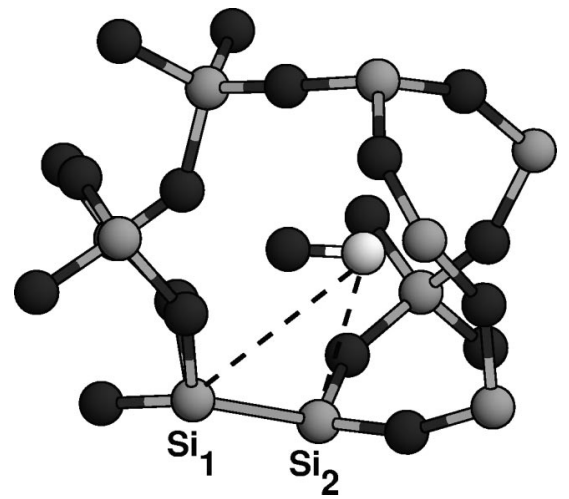

FIG. 6. $\mathrm{CO}$ molecule adjacent to oxygen vacancy, $\mathrm{CO}_{i}+\mathrm{V}_{\mathrm{O}}$. Only the vicinity of the defect is shown. Oxygen, dark; silicon, light; carbon, white. C-O distance $1.1 \AA$, Si-Si distance $2.33 \AA$, $\mathrm{Si}_{1}-\mathrm{C}=3.39 \AA, \mathrm{Si}_{2}-\mathrm{C}=2.7 \AA$.

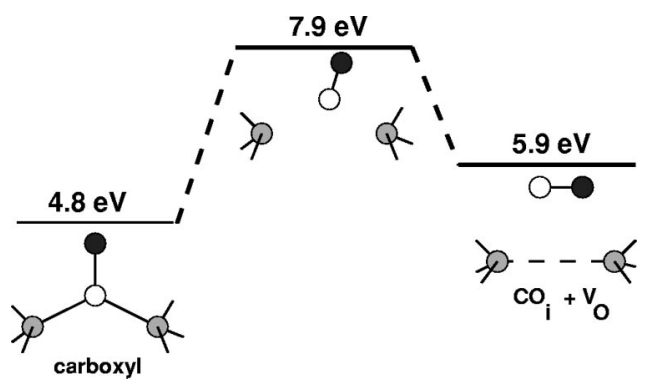

FIG. 7. Schematics of the activation step of the molecular diffusion starting from the carboxyl configuration, Fig. 5, and ending in the $\mathrm{CO}_{i}+\mathrm{V}_{\mathrm{O}}$ configuration, Fig. 6. The saddle point geometry is depicted in Fig. 9. The formation energies of the local minima are given along with the energy of the saddle point in the same scale. Oxygen, dark; silicon, light; carbon, white.

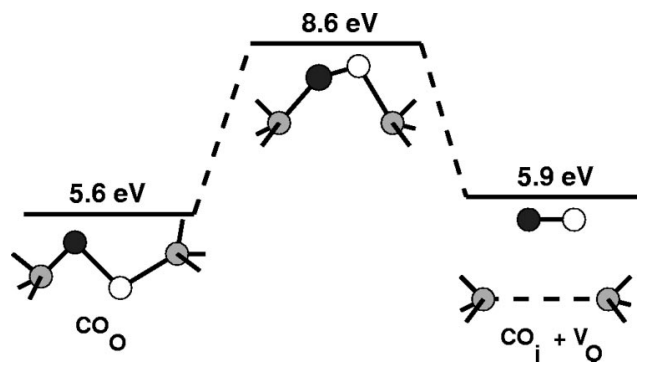

FIG. 8. Schematics of the activation step of the molecular diffusion starting from the $\mathrm{CO}_{\mathrm{O}}$ configuration, Fig. 4, and ending in the $\mathrm{CO}_{i}+\mathrm{V}_{\mathrm{O}}$ configuration, Fig. 6 . The saddle point geometry could not be stabilized. The formation energies of the local minima are given along with the energy of the saddlepoint in the same scale. Oxygen, dark; silicon, light; carbon, white.

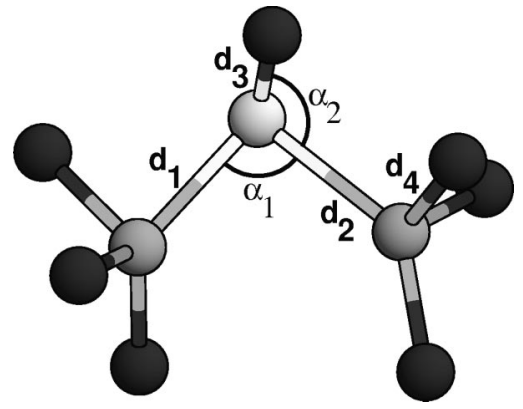

FIG. 9. Saddle point configuration between the carboxyldefect and $\mathrm{CO}_{i}+\mathrm{V}_{\mathrm{O}}$. Only the vicinity of the defect is shown. Oxygen, dark; silicon, light; carbon, white. $d_{1}=1.99 \AA, d_{2}=2.17 \AA, d_{3}$ $=1.21 \AA, d_{4}=1.64 \AA, \alpha_{1}=90^{\circ}, \alpha_{2}=96^{\circ}$.

The last defect we calculated is a $\mathrm{CO}$ molecule adjacent to an oxygen vacancy, $\mathrm{CO}_{i}+\mathrm{V}_{\mathrm{O}}$. This configuration could also be involved in the removal of built-in carbon from the $\mathrm{SiO}_{2}$ lattice. The geometry is shown in Fig. 6. The Si-Si distance of $2.33 \AA$ is close to that in the oxygen vacancy in pure $\alpha$-quartz, which is $2.32 \AA$ in our calculations and $2.43 \AA$ according to Pacchioni and Ieranò. ${ }^{28}$

The $\mathrm{C}_{i}$ and $\mathrm{CO}_{i}+\mathrm{V}_{\mathrm{O}}$ configurations, which have intermediate formation energies, could be expected to occur as transient positions in the diffusion paths for, in the case of $\mathrm{C}_{i}$, an atomic or, in the case of $\mathrm{CO}_{i}+\mathrm{V}_{\mathrm{O}}$, a molecular diffusion mechanism.

\section{BARRIER HEIGHTS FOR CARBON DEFECTS}

The energetics of the defects indicate that any outdiffusion of carbon will start either from the $\mathrm{CO}_{\mathrm{O}}$ or the carboxyl configuration which have the lowest formation energies. Based on the geometries two possible mechanisms have to be considered.

In the first, molecular, mechanism a $\mathrm{CO}$ molecule is pulled out from either the carboxyl configuration or the $\mathrm{CO}_{\mathrm{O}}$ configuration, leaving an oxygen vacancy and thus giving the configuration $\mathrm{CO}_{i}+\mathrm{V}_{\mathrm{O}}$. For a schematic overview see Figs. 7 and 8 , respectively. The saddle point configuration for the path carboxyl $\rightarrow \mathrm{CO}_{i}+\mathrm{V}_{\mathrm{O}}$ is shown in Fig. 9; the barrier height is $3.1 \mathrm{eV}$ for this direction (see Table IV). The reverse process, the trapping of a $\mathrm{CO}$ molecule by an oxygen vacancy, has a barrier of $2.0 \mathrm{eV}$. This saddle point has one imaginary mode in the vibrational spectrum.

The other possible starting position in this first mecha-

TABLE IV. Diffusion barriers for carbon defects calculated as differences between the total energies of the minima and the saddle point configurations.

\begin{tabular}{lll}
\hline \hline \multicolumn{1}{c}{ Path $a \rightarrow b$} & $a \rightarrow b$ & $a \leftarrow b$ \\
\hline Carboxyl $\rightarrow \mathrm{CO}_{i}+\mathrm{V}_{\mathrm{O}}$, Fig. 7 & $3.1 \mathrm{eV}$ & $2.0 \mathrm{eV}$ \\
$\mathrm{CO}_{\mathrm{O}} \rightarrow \mathrm{CO}_{i}+\mathrm{V}_{\mathrm{O}}$, Fig. 8 & $3.0 \mathrm{eV}$ & $2.7 \mathrm{eV}$ \\
$\mathrm{CO}_{\mathrm{O}} \rightarrow \mathrm{C}_{i}$, Fig. 10 & $2.7 \mathrm{eV}$ & $0.6 \mathrm{eV}$ \\
$\mathrm{CO}_{\mathrm{O}} \rightarrow \mathrm{CO}_{\mathrm{O}}$, Fig. 12 & $2.0 \mathrm{eV}$ & $2.0 \mathrm{eV}$ \\
Carboxyl $\rightarrow \mathrm{CO}_{\mathrm{O}}$, Fig. 14 & $1.6 \mathrm{eV}$ & $0.8 \mathrm{eV}$ \\
\hline \hline
\end{tabular}



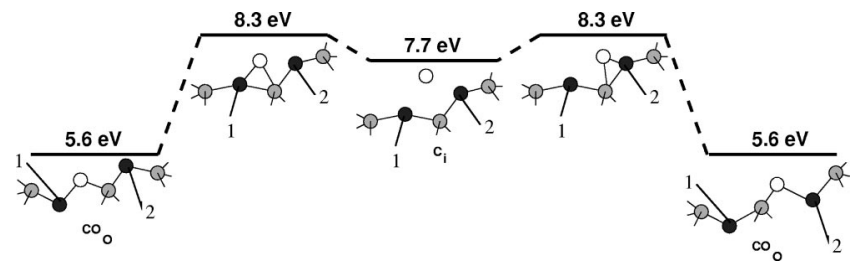

FIG. 10. Schematics of the atomic diffusion mechanism starting from the $\mathrm{CO}_{\mathrm{O}}$ configuration, Fig. 4. The carbon atom is then in the $\mathrm{C}_{i}$ configuration, Fig. 3, before entering another $\mathrm{CO}_{\mathrm{O}}$ configuration. The saddle point geometry is depicted in Fig. 11. The formation energies of the local minima are given along with the energy of the saddle point in the same scale. Oxygen, dark; silicon, light; carbon, white.

nism is the $\mathrm{CO}_{\mathrm{O}}$ configuration. The saddle point between the $\mathrm{CO}_{\mathrm{O}}$ configuration and the $\mathrm{CO}_{i}+\mathrm{V}_{\mathrm{O}}$ configuration could not be stabilized because an electronic level crossing leads to a sharp decrease of total energy in the geometrical vicinity of the saddle point. However, the maximum of the total energy on this path is $3.0 \mathrm{eV}$ above the energy of the $\mathrm{CO}_{\mathrm{O}}$ configuration.

Once a $\mathrm{CO}$ molecule has been formed, the diffusion barriers appear to be very low. Our calculation indicates a very shallow potential energy hypersurface with a barrier $<0.4 \mathrm{eV}$ for the movement of the $\mathrm{CO}$ molecule away from the vacancy in the $c$-channel direction.

The second atomic mechanism involves the $\mathrm{CO}_{\mathrm{O}}$ and $\mathrm{C}_{i}$ configurations as local minima along the path; see Fig. 10 for an overview. The carbon atom starts from a $\mathrm{CO}_{\mathrm{O}}$ configuration next to oxygen atom 1 . It then enters through a barrier of $2.7 \mathrm{eV}$, the intermediate $\mathrm{C}_{i}$ configuration. The barrier from the $\mathrm{C}_{i}$ configuration to the next $\mathrm{CO}_{\mathrm{O}}$ configuration is only $0.6 \mathrm{eV}$; the carbon atom is then next to oxygen atom 2 . The geometry of the saddle point is shown in Fig. 11. (The barrier height for the step $\mathrm{CO}_{\mathrm{O}} \rightarrow \mathrm{C}_{i}$ was estimated by moving all atoms from their initial to their final position on straight lines without any relaxation. By this we can only estimate an absolute upper limit. However, because of the defect formation energies, the lower limit for the barrier in the direction $\mathrm{CO}_{\mathrm{O}} \rightarrow \mathrm{C}_{i}$, is at least $2.1 \mathrm{eV}$. We will use $2.7 \mathrm{eV}$ in this paper.)

To proceed further on this path the carbon atom has to interchange position with oxygen atom 2; see Fig. 10. There are two possible paths. The first path is depicted in Fig. 12 and proceeds directly from $\mathrm{CO}_{\mathrm{O}}$ to $\mathrm{CO}_{\mathrm{O}}$ configuration via the

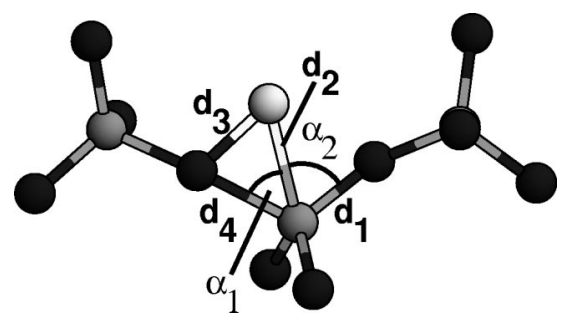

FIG. 11. Saddle point configuration between the $\mathrm{CO}_{\mathrm{O}}$ and the $\mathrm{C}_{i}$ configuration. Only the vicinity of the defect is shown. Oxygen, dark; silicon, light; carbon, white. $d_{1}=1.62 \AA, d_{2}=2.12 \AA, d_{3}$ $=1.63 \AA, d_{4}=1.89 \AA, \alpha_{1}=47^{\circ}, \alpha_{2}=72^{\circ}$.

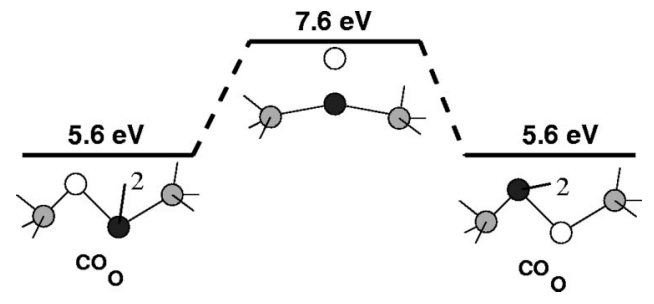

FIG. 12. Schematics of the interchange step of the atomic diffusion starting and ending in the $\mathrm{CO}_{\mathrm{O}}$ configuration, Fig. 4. The saddle point geometry is depicted in Fig. 13. The formation energies of the local minima are given along with the energy of the saddle point in the same scale. Oxygen, dark; silicon light; carbon, white.

saddle point configuration in Fig. 13 without the carbon occupying other local minima. The second path involves the carboxyl configuration as an intermediate local minimum; see Fig. 14 for an overview and Fig. 15 for the saddle point. The maximum barrier heights of these two interchange paths are within $2.0 \mathrm{eV}$ and $1.6 \mathrm{eV}$, respectively, in the same magnitude. The highest barrier in the whole atomic diffusion mechanism is, therefore, $2.7 \mathrm{eV}$ (upper limit), to be required for the activation of $\mathrm{CO}_{\mathrm{O}} \rightarrow \mathrm{C}_{i}$.

The free interstitial position $\mathrm{C}_{i}$ becomes unstable in the presence of an adjacent oxygen vacancy; i.e., the carbon combines with the vacancy. Thus the diffusion of atomic carbon is likely to be disrupted if oxygen vacancies remain due to a lack of oxygen near the $\mathrm{SiC} / \mathrm{SiO}_{2}$ interface.

As mentioned above the interaction between an oxygen vacancy and an interstitial $\mathrm{CO}$ molecule is weak. This is indicated by the low barrier of $<0.4 \mathrm{eV}$ for the dissociation of $\mathrm{CO}_{i}+\mathrm{V}_{\mathrm{O}}$ into $\mathrm{V}_{\mathrm{O}}$ and a seperate free $\mathrm{CO}$ molecule and a high barrier of $2.0 \mathrm{eV}$ for the trapping process $\mathrm{CO}_{i}+\mathrm{V}_{\mathrm{O}}$ $\rightarrow \mathrm{CO}_{\mathrm{O}}$ as mentioned earlier. The behavior of an oxygen molecule, initially in a configuration similar to a $\mathrm{CO}_{i}+\mathrm{V}_{\mathrm{O}}$ configuration, is very different from that. There is no metastable state for the $\mathrm{O}_{2}$ molecule in the $\mathrm{CO}_{i}+\mathrm{V}_{\mathrm{O}}$ )-like configuration. Instead, the oxygen molecule is trapped in the vacancy, forming a peroxyl defect. These two observationsthe weak interaction of the $\mathrm{CO}$ molecule with the vacancy opposed to the strong interaction between the vacancy and the $\mathrm{O}_{2}$ molecule - could explain the experimental finding of

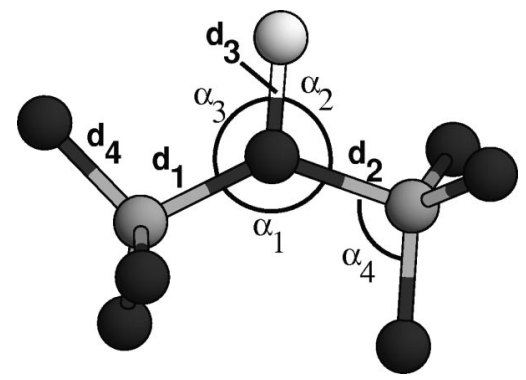

FIG. 13. Saddle point configuration between two $\mathrm{CO}_{\mathrm{O}}$ configurations, Fig. 4, of carbon. Only the vicinity of the defect is shown. Oxygen, dark; silicon, light; carbon, white. $d_{1}=1.74 \AA, d_{2}$ $=1.72 \AA, d_{3}=1.38 \AA, d_{4}=1.60 \AA, \alpha_{1}=134^{\circ}, \alpha_{2}=106^{\circ}, \alpha_{3}$ $=119^{\circ}, \alpha_{4}=107^{\circ}$. 


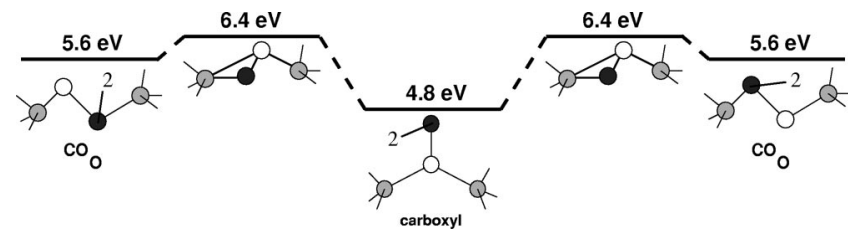

FIG. 14. Schematics of the path between the carboxyl configuration, Fig. 5, and the $\mathrm{CO}_{\mathrm{O}}$ configuration, Fig. 6. The saddle point geometry is depicted in Fig. 15. The formation energies of the local minima are given along with the energy of the saddle point in the same scale. Oxygen, dark; silicon, light; carbon, white.

a fast outdiffusion of carbonaceous species, once they have formed, and a slower indiffusion of oxygen in connection with the oxidation of $\mathrm{SiC}$.

\section{CONCLUSION}

We have calculated the formation energies and diffusion barriers of carbon-related point defects in $\mathrm{SiO}_{2}$ ( $\alpha$-quartz). We have found two interstitial configurations, the carboxyl defect (which has the lowest formation energy of all defects investigated) and a split interstitial with oxygen $\left(\mathrm{CO}_{\mathrm{O}}\right)$ which have significantly lower formation energies than either substitutionals. The interstitials also represent a likely defect configuration at $\mathrm{SiC} / \mathrm{SiO}_{2}$ interfaces or in TEOS-grown $\mathrm{SiO}_{2}$ layers on $\mathrm{Si}$, leading to degradation of device performance in both cases. There are two possible mechanisms for the removal and outdiffusion of carbon from these interstitial positions. A CO molecule can be extracted from these defects with an activation energy of $<3.1 \mathrm{eV}$. The $\mathrm{CO}$ molecule then diffuses without a strong coupling to the lattice with a barrier of $<0.4 \mathrm{eV}$. Recapture by an oxygen vacancy is prevented by a barrier of $2 \mathrm{eV}$, unlike in the case of $\mathrm{O}_{2}$ which is easily trapped again. Alternatively, an unbonded $\mathrm{C}_{i}$ intersti-

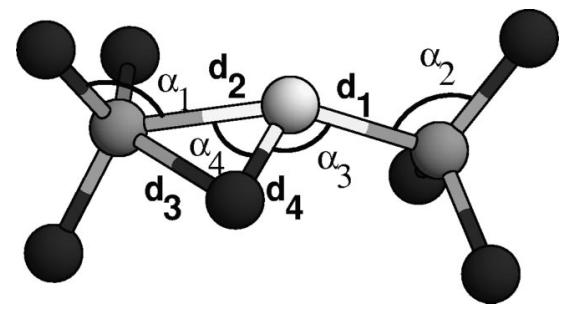

FIG. 15. Saddle point configuration between the carboxyl defect and $\mathrm{CO}_{\mathrm{O}}$. Only the vicinity of the defect is shown. Oxygen, dark; silicon, light; carbon, white. $d_{1}=1.88 \AA, d_{2}=1.98 \AA, d_{3}$ $=1.80 \AA, \quad d_{4}=1.33 \AA, \quad \alpha_{1}=104^{\circ}, \quad \alpha_{2}=106^{\circ}, \quad \alpha_{3}=43^{\circ}, \quad \alpha_{4}$ $=78^{\circ}$.

tial can be extracted from the $\mathrm{CO}_{\mathrm{O}}$ configuration and recaptured at the next oxygen site. The highest barrier in this diffusion process is $2.7 \mathrm{eV}$. These results show that carbon atoms can be removed from a continous network of $\mathrm{SiO}_{2}$ with an activation energy between 2.7 and $3.1 \mathrm{eV}$. On the other hand, $\mathrm{CO}$ can diffuse with a very low $(0.4 \mathrm{eV})$ barrier in silica.

Our findings regarding the $\mathrm{CO}$ extraction and diffusion are in good qualitative agreement with the results of experiments Krafcsik et al. ${ }^{2,31}$ which indicate that carbon diffusion does not start through high-quality $\mathrm{SiO}_{2}$ up to temperatures in excess of $900^{\circ} \mathrm{C},{ }^{32}$ but then it proceeds very fast. They also show that at the temperature used for the oxidation of $\mathrm{SiC}\left(\approx 1200^{\circ} \mathrm{C}\right)$, the removal of carbon from the interface should not be limited by the diffusion of $\mathrm{C}$ through the oxide.

\section{ACKNOWLEDGMENTS}

The authors wish to acknowledge support through DFG Grant No. Fr889/12 and the Hungarian-German bilateral Project MTA-DFG, No. 112.
${ }^{1}$ V. V. Afanasev, M. Bassler, G. Pensl, and M. Schulz, Phys. Status Solidi B 162, 321 (1997).

${ }^{2}$ O. H. Krafcsik, Gy. Vida, I. Pócsik, K. V. Josepovits, and P. Deák, Jpn. J. Appl. Phys., Part 1 40, 2197 (2001).

${ }^{3}$ Z. Zheng, R. E. Tressler, and K. E. Spear, J. Electrochem. Soc. 137, 854 (1990).

${ }^{4}$ J. Mikkelsen, Jr., Appl. Phys. Lett. 45, 1187 (1984).

${ }^{5}$ F. J. Norton, Nature (London) 191, 701 (1961).

${ }^{6}$ D. R. Hamann, Phys. Rev. Lett. 81, 3447 (1998).

${ }^{7}$ J. R. Chelikowsky, D. J. Chadi, and N. Binggeli, Phys. Rev. B 62, R2251 (2000).

${ }^{8}$ I. Mizushima, E. Kamiya, N. Arai, M. Sonoda, M. Yoshiki, S. Takagi, M. Wakamiya, S. Kambayashi, Y. Mikata, S. Mori, and M. Kashiwagi, Jpn. J. Appl. Phys., Part 1 36, 1465 (1997).

${ }^{9}$ K. Sano, S. Hayashi, S. Wickramanayaka, and Y. Hatanaka, Thin Solid Films 282, 397 (1996).

${ }^{10}$ J. D. Kalen, R. S. Boyce, and J. D. Cawley, J. Am. Chem. Soc. 74, 203 (1991).

${ }^{11}$ M. Heggie, R. Jones, C. D. Latham, S. Maynard, and P. Tole, Philos. Mag. B 65, 463 (1992).
${ }^{12}$ A. Edwards and W. B. Fowler, Phys. Rev. B 26, 6649 (1982).

${ }^{13}$ M. Elstner, D. Porezag, G. Jungnickel, J. Elsner, M. Haugk, Th. Frauenheim, S. Suhai, and G. Seifert, Phys. Rev. B 58, 7260 (1998).

${ }^{14}$ Th. Frauenheim, G. Seifert, M. Elstner, Z. Hajnal, G. Jungnickel, D. Porezag, S. Suhai, and R. Scholz, Phys. Status Solidi B 217, 41 (2000).

${ }^{15}$ D. Porezag, Th. Frauenheim, Th. Köhler, G. Seifert, and R. Kaschner, Phys. Rev. B 51, 12947 (1995).

${ }^{16}$ R. Kaschner, T. Frauenheim, T. Köhler, and G. Seifert, J. Comput Aided Mater. Design 4, 53 (1997).

${ }^{17}$ E. Rauls, R. Gutierrez, J. Elsner, and Th. Frauenheim, Solid State Commun. 111, 459 (1999).

${ }^{18}$ E. Rauls, T. Lingner, Z. Hajnal, S. Greulich-Weber, Th. Frauenheim, and J.-M. Spaeth, Phys. Status Solidi B 217/2, R1 (2000).

${ }^{19}$ E. Rauls, Z. Hajnal, P. Deák, and Th. Frauenheim, Phys. Rev. B (accepted).

${ }^{20}$ R. Doremus, J. Electrochem. Soc. 143, 1992 (1996).

${ }^{21}$ R. W. G. Wyckoff, Crystal Structures (Interscience, New York, 1963). 
${ }^{22}$ T. Di Stefano and D. E. Eastman, Solid State Commun. 9, 2259 (1991)

${ }^{23}$ Yong-nian Xu and W. Y. Ching, Phys. Rev. B 44, 11048 (1991).

${ }^{24}$ N. Binggeli, N. Troullier, J. L. Martins, and J. R. Chelikowsky, Phys. Rev. B 44, 4771 (1991).

${ }^{25}$ Z. Fang, X. Guo, S. A. Canney, S. Utteridge, M. J. Ford, I. E. McCarthy, A. S. Kheifets, M. Vos, and E. Weigold, Phys. Rev. B 57, 4349 (1998).

${ }^{26}$ M. Kaukonen, R. M. Nieminen, P. Sitch, G. Jungnickel, D. Porezag, Th. Frauenheim, and S. Poykko, Phys. Rev. B 57, 9965 (1998).

${ }^{27}$ G. T. Barkema and N. Mousseau, Phys. Rev. Lett. 77, 4358 (1996).

${ }^{28}$ G. Pacchioni and G. Ieranò, Phys. Rev. B 56, 7304 (1997).
${ }^{29}$ H. Monkhorst and D. Pack, Phys. Rev. B 13, 5188 (1976).

${ }^{30}$ The formation energies in the table are with respect to the $\mathrm{O}_{2}$ molecule. For the conversion from $-0.7 \mathrm{eV}$ with respect to atomic oxygen given in Ref. 28 half of the calculated dissociation energy of $\mathrm{O}_{2}, 2.4 \mathrm{eV}$, was added as suggested by the authors of Ref. 28 themselves. This $2.4 \mathrm{eV}$ was also applied to the $-0.86 \mathrm{eV}$ formation energy of the peroxyl defect calculated by Hamann. For the SCC-DFTB results half of the total energy of the $\mathrm{O}_{2}$ molecule as calculated with SCC-DFTB including spin polarization contributions is used as reference.

${ }^{31}$ O. H. Krafcsik, K. V. Josepovits, P. Deák, L. Tóth, and B. Pécz (unpublished).

${ }^{32}$ Note that in those experiments carbon comes either from an $a-\mathrm{C}:(\mathrm{H}, \mathrm{O}) / \mathrm{SiO}_{2}$ interface or from a $\mathrm{CO}$ gas above $\mathrm{SiO}_{2}$. 